\title{
TURISMO DE EVENTOS: LOS CRUCEROS ESPAÑOLES EN LA INAUGURACIÓN DEL CANAL DE SUEZ DE 1869
}

\author{
Gaetano Cerchiello \\ Universidad de Alicante
}

\section{RESUMEN}

El 17 de noviembre de 1869 tuvo lugar el solemne acto de inauguración del Canal de Suez. Largamente celebrado por los medios de información, el histórico acontecimiento atrajo visitantes de toda Europa, generando asimismo la promoción de varios viajes organizados. Tras una breve introducción sobre los principales hechos que condujeron a la apertura de la nueva ruta marítima, este artículo se ocupa de dos singulares proyectos de cruceros turísticos españoles, en una época en la que los viajes de recreo al extranjero, y el turismo en general, sólo proliferaban entre las élites foráneas. Su estudio ayuda a esclarecer, por otra parte, algunos rasgos diferenciales de las primeras experiencias crucerísticas en España, que habían empezado a llevarse a cabo desde mediados del siglo XIX.

Palabras claves: turismo de eventos, historia de los cruceros, Canal de Suez, transportes, viajes marítimos.

\section{Event tourism: the Spanish cruises in the inauguration of the Suez canal of 1869}

\section{ABSTRACT}

The opening ceremony of the Suez Canal took place on 17th November 1869 . This historic event, which was celebrated at length by the media, attracted visitors from all over Europe thus generating the promotion of several packaged tours. After a brief introduction about the main facts that lead to the opening of the new sea route, this paper will focus on two singular projects of Spanish cruises, at a time when recreational trips abroad, and indeed tourism as a whole, were only proliferating amongst foreign elites. The study of

Recibido: 25 de enero de 2014

Devuelto para su revisión: 5 de septiembre de 2014

Aceptado: 10 de octubre de 2014

Instituto Universitario de Investigaciones Turísticas. Universidad de Alicante. Apartado 99. 03080 ALICANTE (España).E-mail: gaetano.cerchiello@ua.es 
these projects will help shed light on some of the differential features of the first cruise experiences in Spain which started taking place in the mid XIX century.

Key words: tourism of events, history of cruises, The Canal of Suez, transports, maritime trips.

El crucero turístico - es decir, el viaje organizado a bordo de un barco con un propósito puramente de recreo- empezó a gestarse en el Reino Unido a lo largo del siglo XIX ${ }^{1}$. En la base de este suceso, está la introducción de la tecnología del vapor en el ámbito del transporte marítimo, y con ello la creación de las primeras líneas regulares. En España, donde la navegación a vapor se generalizó con algunas décadas de retraso, no fue hasta mediados del siglo XIX cuando el viaje marítimo de recreo hizo su aparición. En sus orígenes, se caracterizó por ser una actividad ocasional y de carácter local, siendo Barcelona y Palma de Mallorca las localidades pioneras de esta novedosa actividad ${ }^{2}$. Sin embargo, las iniciativas finalizadas a poner en marcha las expediciones de larga duración fracasaron, generalmente por falta de clientela, dejando el paso a la realización de breves excursiones, sin pernoctación. Éstas últimas, por el contrario, solían registrar un elevado número de participantes. Ante este escenario, y con el propósito de fomentar un mayor interés entre las clases acomodadas de la época, armadores y navieras trataron de promover las largas travesías en coincidencia con algún evento de gran resonancia. En febrero de 1861, por ejemplo, había sido la recién constituida compañía Antonio López la que había intentado llevar a cabo un «gran viaje de recreo» a Tetuán, unos días después de la conquista de la ciudad marroquí por parte de las tropas españolas ${ }^{3}$. Ninguna de estas iniciativas, no obstante, consiguió materializarse. A este propósito, cabe recordar que el hecho de asociar un acontecimiento de relevancia con el propósito principal de un viaje de placer, fue en aquella época un recurso muy difuso. Prueba de ello son algunas de las primeras experiencias organizativas de Thomas Cook en el Reino Unido, como el package tour a París en 1855 con motivo de la Exposición Universal ${ }^{4}$. Esta estrecha relación entre viaje organizado y evento se hace evidente también en la práctica excursionista. Ya en septiembre de 1825, por ejemplo, la botadura del HMS Princess Charlotte, un buque de guerra de la Armada Real británica, había implicado la puesta en marcha de un recreational day trip de Southampton a Portsmouth a bordo de un buque vapor ${ }^{5}$. En las páginas que siguen, se tratará de añadir nuevos datos sobre este fenómeno, centrando la atención en dos iniciativas crucerísticas que se promovieron en España en 1869. Pero antes, hemos de dar cuenta del extraordinario suceso que las motivó.

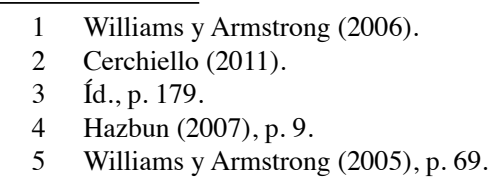




\section{EGIPTO: DE RUTA TERRESTRE A RUTA MARÍTIMA}

Si bien la idea de abrir una vía navegable que uniera el Mediterráneo al mar Rojo pertenecía a la «más remota antigüedad», no fue hasta mediados del siglo XIX cuando ésta despertó el interés de las grandes potencias europeas, a raíz de la fuerte expansión comercial que implicaba la necesidad de mejorar las vías de comunicación con Oriente ${ }^{6}$. Los inconvenientes del paso por el Cabo de Buena Esperanza se habían hecho aún más patentes con el desarrollo de la navegación a vapor en la primera mitad de siglo. Los elevados costes de la amplia travesía, y especialmente la dificultad de aprovisionamiento del carbón, limitaban el empleo de las nuevas embarcaciones a lo largo de esta ruta. Se reforzaban así los argumentos a favor de una vía más segura, más breve, y que garantizara sobre todo una mayor rapidez y regularidad de las operaciones. A razón de ello, el gobierno británico había establecido desde 1840 una nueva vía de comunicación regular con las colonias asiáticas, que obviaba la circunnavegación del continente africano mediante el tránsito terrestre por Egipto ${ }^{7}$. Instituida con el fin de mejorar ante todo el servicio de la correspondencia, la nueva ruta marítimo-terrestre, conocida como la Overland Route a la India, se organizó de la siguiente forma: un buque vapor de la Peninsular and Oriental Steam Navigation Company, la naviera adjudicataria del contrato de conducción del correo, unía Inglaterra con Egipto mediante un servicio mensual entre Southampton y Alejandría, con escalas intermedias en los puertos mediterráneos de Gibraltar y Malta. Una vez pisado el suelo egipcio, el viaje proseguía a bordo de pequeños vapores fluviales hasta la ciudad de El Cairo. Desde allí, una caravana de carruajes y camellos cruzaba el desierto para llegar al puerto de Suez, a orillas del mar Rojo, donde otro barco de la misma compañía hacía rumbo a la isla de Ceilán ${ }^{8}$. El atajo demostró ser efectivo. Las autoridades ingleses decidieron aumentar la frecuencia del servicio postal con dos viajes mensuales, y posteriormente extenderlo incluso hacia Australia. La reducción de las distancias se tradujo en una considerable disminución de la duración del viaje. Además, la navegación a vapor garantizaba regularidad a las comunicaciones. El viaje entre Southampton y Ceilán llegó a estabilizarse en torno a los 35 días, disminuyendo a los 30 días a mediados de los años sesenta. Más difícil establecer el tiempo medio necesario para efectuar el mismo desplazamiento siguiendo la derrota por el Cabo de Nueva Esperanza. Este último camino variaba notablemente en función del tipo de navegación (vela o mixto), tipo y calidad del buque, época del año, etc. No obstante, según las fuentes de la época, no solía ser inferior a los 75 días $^{9}$.

Otras naciones, como Francia y Austria, se sumaron a la iniciativa. Los gobiernos de ambos países promovieron sendas líneas regulares para transportar la propia correspondencia hacia Alejandría, todo ello en coincidencia con las operaciones de los buques ingleses.

\footnotetext{
$6 \quad$ Navarro (1870), p. 41.

7 Howarth y Howarth (1987), pp. 23-36; Poole y Sassoli-Walker (2013), pp. 13-15; Di Nolfo (1959).

8 La comunicación fluvial entre Alejandría y El Cairo comprendía dos distintos tramos: el primero se realizaba por el recién construido canal de Mahmudiya, mientras que el segundo, a bordo de otra embarcación, consistía en recorrer aproximadamente unas 100 millas del río Nilo, antes de llegar a la capital egipcia. Estas informaciones proceden de los diarios de viajes de Ortiz de Zarate (1848), pp. 40-62; De Santos (1851), pp. 82-99; García Del Canto (1862), pp. 147-160.
}

9 Navarro (1870), pp. 62-72. 
En cuanto al correo oficial español, la «situación del erario» imposibilitaba establecer un servicio regular con la colonia de Filipinas mediante buques de matrícula nacional. Por este motivo, desde finales de 1845, el gobierno consideró «útil» aprovechar las escalas de los vapores ingleses por el puerto de Gibraltar, poniendo fin al «método lento e incierto» seguido hasta entonces ${ }^{10}$. Y aproximadamente 15 años después, en virtud de una Real Orden del 18 de mayo de 1860, la correspondencia española siguió también la llamada «vía de Marsella» ${ }^{11}$. A tal efecto, se establecía que todo el servicio de correo con la colonia asiática saldría desde Marsella en los buques franceses con rumbo a Alejandría, con la única excepción de la correspondencia que procedía de las provincias «más próximas» a Gibraltar. La nueva ruta por Egipto aportaba grandes beneficios también al tráfico de pasajeros. La reducción de las distancias y la regularidad de las operaciones les permitía llegar a destino con antelación y en las fechas programadas; todo ello obviamente a cambio de pagar una tarifa superior a la que solían cobrar las embarcaciones que cruzaban el Cabo de Buena Esperanza.

Todas las ventajas anteriormente citadas desaparecían a la hora de aplicarse al tránsito de las mercancías. La complejidad de las operaciones de tierra, los medios utilizados, los continuos transbordos y el incremento de los costes que esto suponía, impedían que la Overland Route pudiera asumir una parte significativa del comercio entre Oriente y Occidente. Más allá de desviar el tránsito de aquellos géneros de poco volumen y alto valor unitario, la vía de Egipto se mostraba como una alternativa escasamente practicable. Ni siquiera la construcción de una línea de ferrocarril entre Alejandría y El Cairo, que se abrió al tráfico a mediados de 1854, aportó la solución al problema. La dirección del comercio no mostró de hecho ningún cambio de tendencia. El tonelaje inglés por el Cabo de Buena Esperanza, por ejemplo, registró un incremento anual de 134.000 toneladas entre 1854 y $1857^{12}$.

Aun cuando el indicado camino de hierro favorezca efectivamente la correspondencia y a los viajeros, no queda comprendido en este beneficio la parte más esencial, a saber: el tráfico y los artículos mercantiles, puestos que éstos habría de cargarse y descargarse cuatro veces, resultando con esta operación tales averías, tal pérdida de tiempo y de dinero, que por último sería preferible el camino del $\mathrm{Cabo}^{13}$.

Pero como los acontecimientos futuros acabarían demostrando, la ruta elegida era la correcta. En noviembre de 1856, la revista inglesa Fraser's Magazine argüía que el camino a través del Mediterráneo y el mar Rojo cumplía en realidad «all the conditions of a quick, cheap, and certain passage to India» ${ }^{14}$. Al fin y al cabo, el cúmulo de inconvenientes que ésta implicaba para el comercio habrían desaparecido con la «conversion of that overland route into a ship route». De acuerdo con la opinión mayoritaria de la época, y en contra de la posición oficial del propio gobierno, la revista señalaba que el

10 Gaceta de Madrid, 1 de noviembre de 1845.

11 Legislación Ultramarina, 1865, p. 542.

12 Los males y los remedios, tomo II, p. 46.

13 La Ilustración, 14 de enero de 1856, p. 19.

14 Fraser's Magazine, n 323, noviembre de 1856, pp. 574-581. 
verdadero argumento a favor de la apertura de una vía navegable entre el Mediterráneo y el Mar Rojo era que «the route opened by it is a ship route from beginning to end» ${ }^{15}$.

En la época en la que la publicación inglesa argumentaba sus razones, el proyecto del Canal de Suez ya estaba en marcha. Exactamente dos años antes, el 30 de noviembre de 1854, el ex cónsul francés en Alejandría, Ferdinand de Lesseps, había recibido del Virrey de Egipto el derecho y privilegio exclusivos de crear una empresa para construir un «passage propre à la grande navigation» entre los dos mares ${ }^{16}$. El respaldo de la comunidad científica a la viabilidad de la obra, que se materializó en un informe favorable de una comisión de ingenieros y marinos designados por los gobiernos de las principales potencias europeas, había conferido plena credibilidad al proyecto, sentando las bases para su futura realización. En efecto, tal como explicaba el delegado español, Cipriano Segundo Montesino, este organismo resolvió que «ningún obstáculo serio» se oponía a la apertura de una vía navegable, considerándola incluso «necesaria» para «los intereses generales de la civilización» ${ }^{17}$. La labor de los científicos incluyó también el análisis y la comparación con «todos los trazados propuestos» en los últimos 50 años, «a fin de que ninguna duda quedase» sobre «el mejor medio de unir ambos mares». De este modo, se refutaba la principal objeción técnica a la construcción del canal, que residía en la supuesta «diferencia de nivel entre las aguas» de los dos mares ${ }^{18}$. El otro avance decisivo fue la suscripción íntegra del capital social de la Compagnie Universelle du Canal Maritime de Suez, la sociedad anónima responsable de la construcción y explotación comercial del canal, lo que significaba disponer de los medios financieros necesarios para llevar a cabo la «colosal» obra. El capital social se componía de 400.000 acciones de 500 francos cada una, por un valor total de 200 millones de francos, equivalente al coste inicialmente previsto para la realización de la obra ${ }^{19}$. Los trabajos se iniciaron en abril de 1859, y consistieron principalmente en la apertura de un canal marítimo de poco más de $160 \mathrm{~km}$. de longitud en la parte más estrecha del llamado istmo de Suez, entre la homónima localidad a orillas del mar Rojo, y el golfo de Pelusium en la costa mediterránea. Pese a una amplia serie de vicisitudes y retrasos, la construcción del canal quedó prácticamente terminada a finales de la década siguiente, y la anhelada unión entre Oriente y Occidente se había hecho realidad ${ }^{20}$.

Para celebrar el histórico suceso, el gobierno egipcio invitó a las máximas autoridades políticas extranjeras, y otros centenares de personalidades, a participar en el solemne acto de inauguración, que finalmente tendría lugar el 17 de noviembre de 1869.

15 Íd.

16 Piquet (2008).

17 Montesino (1857). Una pequeña delegación de científicos había llegado por primera vez a Egipto el 18 de noviembre de 1855, y una vez finalizada la inspección, había entregado el 3 de enero de 1856 un primer documento al Virrey, informándole que la ejecución del canal podía considerarse «fácil» y su éxito «seguro»; dos días después, fue firmada la concesión definitiva a favor de Lesseps, que revisaba parcialmente la de noviembre de 1854 .

$18 I$ Id.

19 Constitution de la Compagnie universelle, pp. 17-64; Piquet (2008), p. 68.

20 Montero y Bocanegra (1998), pp. 610-613. Un plano del canal en Navarro (1870), p. 104. 


\section{LA AFLUENCIA DE VIAJEROS HACIA PORT SAID}

Anunciada como una de las «conquistas más grandes del espíritu humano», las noticias procedentes de Egipto llenaron las páginas de los diarios españoles en los meses previos al suceso. En los círculos científicos y literarios del país, la apertura del canal acabó por convertirse en el principal tema de conversación ${ }^{21}$. Los medios de información habían dedicado amplio espacio al proyecto desde el comienzo de las obras de construcción, mostrando en todo caso un apoyo incondicionado. Una y otra vez habían reiterado la «necesidad» y la «conveniencia» de llevar a cabo la «magnífica» empresa, así como los «indecibles» beneficios y las «incalculables» consecuencias que iba a suponer «tanto en el mundo político, como en el mercantil» 22 . Las alabanzas públicas hacia el presidente de la Compañía, Ferdinand de Lesseps, eran incesantes. Universalmente reconocido como el gran artífice de la hazaña, los inconvenientes y obstáculos con los que tropezó su proyecto - principalmente la oposición del gobierno inglés - no minaron su figura ante la opinión pública. Por el contrario, le confirieron a la postre una imagen heroica ${ }^{23}$. A los reconocimientos de la prensa, se añadían numerosas distinciones oficiales. Una de éstas llegó también de las Cortes Constituyentes españolas. Por unanimidad se aprobaba una proposición para asociarse al «júbilo inmenso con que el mundo entero, saluda[ba] la inauguración del Canal de Suez», y se declaraba que Lesseps «se ha[bía] hecho acreedor a la gratitud de la humanidad, sin distinciones de nacionalidades ni de raza ${ }^{24}$. A medida que se aproximaba el «gran día» de la inauguración, la admiración que se le expresaba en España alcanzaba los límites de la idolatría. Si los antiguos le «hubieran hecho Dios a Lesseps — reiteraba el diario El Imparcial - los modernos le han considerado más, y la Europa admirada le saluda hoy como el primer conquistador de la tierra ${ }^{25}$. Unos días más tarde, la revista El Museo Universal recordaba que «en una integridad de fuerzas admirable», este «hombre extraordinario» había formulado un proyecto «colosal», después de sostener una «guerra titánica contra los enemigos de la obra ${ }^{26}$. En otras palabras, Ferdinand de Lesseps se había convertido en «apóstol y casi mártir del más decisivo y trascendental proyecto» del siglo XIX.

En este clima de entusiasmo y expectación, no es de extrañar que muchos ciudadanos anhelaran unirse al concurso de soberanos, ministros y otros ilustres convidados a las fastuosas fiestas que iban a empezar en Puerto Said, la ciudad ubicada en la embocadura del canal en la costa mediterránea egipcia, que había surgido tras el comienzo de las obras en 1859. En una valiosa memoria de su viaje, Lázaro Bardón, uno de los invitados españoles a la ceremonia de inauguración, narra lo siguiente:

Con efecto, la fama de las fiestas que allí se preparaban llenaba la vieja Europa, y de todas las naciones que la pueblan afluían viajeros a las orillas del Mediterráneo, esperando buques de vapor que los condujesen a la histórica tierra de los faraones ${ }^{27}$.

21 Bardón (1870), prólogo, p. VIII.

22 La Ilustración, 14 de enero de 1856, pp. 19-21; La Época, 15 de marzo de 1856, p. 4; El Clamor Público, 5 de julio de 1856, p. 1; Gaceta de los Caminos de Hierro, 31 de agosto de 1856, pp. 292-293.

23 Bertrand y Ferrier (1887), pp. 233-288; Azcárraga (1956), pp. 49-52; Hinojo (2008), pp. 169-171.

24 Diario de Sesiones de las Cortes Constituyentes (1870), t. VII, pp. 4354-4355.

25 El Imparcial, 15 de octubre de 1869.

26 El Museo Universal, 31 de octubre de 1869.

27 Bardón (1870), prólogo, p. I. 
El gran evento generó un flujo de pasajeros muy poco habitual para aquella época. Las grandes beneficiarias de esta demanda puntual fueron principalmente las navieras europeas que prestaban servicio regular hacia el norte de Egipto. Entre éstas, destaca la Compagnie des Messageries Impériales, la poderosa naviera francesa que cubría la línea entre Marsella y Alejandría desde $1851^{28}$. En virtud de un convenio con las autoridades egipcias, la compañía recibió el encargo de transportar al numeroso grupo de personalidades destacadas de la cultura, hombres de negocio y reporteros que formaban parte de la amplia lista de convidados europeos. De este modo, mientras las delegaciones oficiales representantes de los distintos gobiernos viajaban a bordo de los respectivos buques de guerra, los invitados particulares fueron congregados primeramente en París, para ser desplazados posteriormente en tren hacia Marsella. Desde allí, se procedió al embarque del pasaje en los vapores de la compañía francesa, que en los días previos a la inauguración tuvo que incrementar sus operaciones de transporte en número y frecuencia. Tres de sus buques, por ejemplo, zarparon «llenos» de pasajeros los días 9 y 10 de noviembre 29 .

La celebración del «verdadero acontecimiento del siglo» ocasionó también la organización de algunas expediciones marítimas de índole más turística. Siempre en Francia, donde la repercusión del evento fue mayor que en cualquier otro país europeo, se promovieron dos cruceros hacia Puerto Said. El primero, con salida desde Marsella el 28 de octubre, brindaba a sus huéspedes un servicio exclusivo de restauración e incluso atención médica, al precio de 500 francos ${ }^{30}$. El segundo, cuyos «cartelones» publicitarios aparecieron por las calles de París a principios de octubre, hacía referencia a un viaje de 18 días por el Mediterráneo, que incluía la oportunidad de cruzar el canal hasta llegar a la ciudad de Suez.

¿Qué hubieran dicho nuestros abuelos — comentaba el diario madrileño El Imparcial - si les hubiesen vaticinado que sus nietos irían hasta el mar Rojo y volverían, después de haber visitado la tierra de los faraones, en menos tiempo que empleaban ellos para ir desde su pueblo hasta la capital del Reino? $?^{31}$

Algo parecido ocurrió también en Italia. La naviera de línea Raffaele Rubattino e $C$. organizó un «viaggio speciale» entre Génova y Port Said a primeros de noviembre, con el fin de ofrecer la «possibilità di assistere a quella solennità». Según indicaban los anuncios de prensa, el programa incluía el tránsito por los puertos de Livorno, Nápoles, Messina y Alejandría, antes de llegar a destino el día 16. A este efecto, la compañía italiana procedía a distribuir el pasaje en dos clases de servicio, y reducir la capacidad máxima de acomodación del barco ${ }^{32}$.

28 Jouham (1878), pp. 122-126; Berneron (2007), pp. 184-185.

29 La información sobre la salida de los vapores Péluse, Guienne, y Godavery en los diarios de viaje de Breittmayer (1870), Bardón (1870), La Bédollière (1870). La noticia también en La Época, 14 de noviembre de 1869 , p. 2 .

30 Karabell (2003), p. 248.

31 El Imparcial, 26 de octubre de 1869, p. 2.

32 El aviso promocional en La Stampa, 7 de octubre de 1869, p. 4. 
Bien distinta la propuesta de Thomas Cook de cara a las élites inglesas. En lugar de emprender un crucero desde las islas británicas, que implicaría el costoso chárter de un buque vapor, el célebre empresario elaboró un complejo pero atractivo paquete turístico, cuyo desplazamiento hasta Port Said se realizaría utilizando los servicios de transporte regular, ferroviario y marítimo. En su segunda experiencia organizativa de una viaje a Egipto y Oriente Medio, y sobre la base de tarifas negociadas con las distintas empresas de transporte y alojamiento, el precursor de los agentes de viajes ofrecía a un precio ventajoso el ulterior aliciente de conocer, durante el trayecto, distintas localidades de la Europa continental. Finalmente, la expedición llegaría al puerto de Brindisi (Italia) para embarcar en un vapor directo a Alejandría. Después de admirar el nuevo Canal y efectuar un breve crucero por el Nilo, el tour se trasladaría hacia Esmirna y Constantinopla, siempre a bordo de buques vapores que efectuaban sus servicios de líneas por el Mediterráneo Oriental ${ }^{33}$.

\section{EL CRUCERO ISTMO DE SUEZ}

Por lo que se refiere a España, la escasa cultura viajera de sus clases acomodadas y la ausencia de agencias de viajes u otras figuras empresariales parecidas, impedían de facto la proposición del modelo de viaje que se promovió en las islas británicas, y que empezaba a estar de moda también en Alemania ${ }^{34}$. Por ello, resultaba mucho más factible organizar un viaje marítimo de placer desde algún puerto del mediterráneo español. A facilitar esta labor contribuía, además, la inexistencia de un servicio de línea marítimo entre España y Egipto, que obligaba por tanto a quienes querían presenciar el evento a desplazarse por cuenta propia hasta un puerto extranjero. Éste por ejemplo fue el camino que emprendieron cinco aristócratas vizcaínos, encabezados por el conde de Peñaflorida. «Afrontando las molestias que entonces tan largo viaje suponía», el pequeño grupo optó por el transporte terrestre hasta Bríndisi, donde finalmente salieron en un vapor italiano rumbo a Port Said el 9 de noviembre ${ }^{35}$.

El primer hecho destacable y novedoso del crucero «Istmo de Suez», cuyo anuncio se publicó por primera vez en el diario El Imparcial el 21 de septiembre de 1869, fue el amplio radio geográfico de su difusión (figura 1). El mismo aviso se divulgó los días siguientes de forma simultánea en varios periódicos españoles, con el claro intento de dirigirse al conjunto de las élites económicas y sociales del país ${ }^{36}$.

A este fin, se habilitó un punto de suscripción en cada una de las siguientes localidades, donde obtener «cuantos pormenores» sobre el viaje y poder formalizar la compra: Alicante, Barcelona, Bilbao, Cádiz, Madrid, Málaga, San Sebastián, Santander, Sevilla y Valencia. El escrito daba amplia información sobre la organización de un «viaje de recreo» desde el puerto de Valencia a principios de noviembre, de una duración aproximada

33 Withey (1997), pp. 257-258. El primer viaje organizado de la agencia de Thomas Cook a Egipto y Oriente Medio había tenido lugar entre primavera y verano del mismo año.

34 Lavaur (1977).

35 Manso de Velasco (1947).

36 El Imparcial, 21 de septiembre de 1869, p. 4. A partir del día siguiente -y hasta el 1 de octubre- el aviso se editó también en la sección comercial de otros periódicos de la capital: La Época, La Correspondencia de España y La Iberia. El mismo anuncio en el Eco de Alicante, 01 de octubre 1869, y Diario de Barcelona, 24 de septiembre de 1869 . 
Figura 1

ANUNCIO DEL VIAJE MARÍTIMO DE RECREO ISTMO DE SUEZ (1869)

\section{ISTMO DE SUEZ.}

Con motiv a is apertura del Canał de Suez, fijada para el 17 de noviembro próxino, so efectuará, si se reore et euficiente número de pssajeros, un viaje de recreo á Egıpu 6 ilailia, con un magnifico rapor de hólice de 600 coneladas, construldo ol oino pasado en lnglatẹrra $\rho$ trréglado con todos lä́ conodidades que requiere esto viaje.

La expodiucu saldé́ de Valencia del 2 al 3 tie novis mbre, haciendo axcala on

regresendo por

\section{ALEJANDRIA, PORT-SAID Y SUEZ.}

\section{PALERIFO, NAPOLES Y CIYITA.VECHLA,}

durark do 40 a 65 dias.

En cada puesto permarecerá el vapor los dias necesarios para quo los sohores riajaros pucdan rigizac ia curiosidades do la siudad y hacer exçurajunos, como:

Des Suer á Cairo u iso Pir thides.

De Nápoles a Pempeya y el Vesurio.

Y do Livita-Vechia é homa.

El preçio del passjo, inciuso la maviutençion, 6 a de pesos fuertes 350 , pagando 6 garatizando pesos fuertes 200 al suscribir y pesos 150 a emb rearso

Deblendo quedar lerminada la suscriciori para e! $10^{\circ}$ de octubro, se supiica blas perso nas que deseen tomar parie en este agradable viaje, se sirvaz dirigirna, antes del cilado 1. de ectubre, álos

Fuente: El Imparcial, 21 de septiembre de 1869.

entre 40 y 45 días. El recorrido no se limitaba a la estancia en Puerto Said para asistir al comienzo de los festejos, sino que incluía una escala previa en Alejandría. Pero sobre todo, se hacía hincapié en la perspectiva de cruzar todo el canal hasta la ciudad de Suez, ofreciendo atractivas excursiones a El Cairo y las Pirámides de Giza. Al regreso de Egipto, la «expedición» continuaría su ruta por el Mediterráneo, efectuando tres sugestivas y largas escalas en Italia, respectivamente en los puertos de Palermo, Nápoles y Civitavecchia. En cada uno de éstos, el barco permanecería los «días necesarios» para que los viajeros pudieran conocer las «curiosidades» de cada ciudad, y hacer las oportunas visitas al Vesubio, Pompeya y Roma. Tras la descripción del itinerario, y de acuerdo con la praxis de la época, se hacía hincapié en que la realización del viaje estaría sujeta a la consecución de un «suficiente número de pasajeros» ${ }^{37}$. Por este motivo, se señalaba la obligatoriedad de abonar 1.000 pts. en concepto de depósito, mientras que el resto se entregaría el día del embarque. El precio total, manutención incluida, estaba fijado en 1.750 pts., tratándose del mismo importe para todos los pasajeros. De hecho, según revelaba el aviso, el «magnifico» vapor de hélice, recién construido y «arreglado con todas las comodidades», ofrecía para este viaje una única clase de servicio. De acuerdo con esta información, por lo tanto, y si tenemos en cuenta que en el año 1869 el sueldo bruto anual por ejercer una cátedra en la

37 Sobre este aspecto, Cerchiello (2011). 
universidad española solía variar entre 2.000 y 2.500 pesetas (en función del organismo convocante, las disciplinas de enseñanza y la antigüedad), resulta lógico deducir que la participación era al alcance de muy pocos afortunados ${ }^{38}$.

A diferencia de la exhaustiva información sobre programa, itinerario, características principales del buque, precios y modalidad de pago, el anuncio no precisaba la identidad del organizador, ni el nombre del barco. No obstante, y aunque sea en el terreno de las hipótesis, es probable que detrás de este proyecto estuviera una iniciativa ajena a las navieras, y que se pondría por lo tanto en marcha mediante el flete del buque. Tres indicios apuntan en esta dirección, señalando de entrada que si para la realización de un viaje de recreo, el alquiler de un vapor era una completa novedad en España, se trataba de una práctica más que habitual en el ámbito del transporte de carga ${ }^{39}$. En primer lugar, cabe aclarar que el mismo hecho de omitir la denominación del organizador no se ajustaba al método adoptado por navieras o armadores de la época. Por regla general, sus espacios publicitarios siempre incluían el propio nombre, y de hecho se caracterizaban por estar encabezados por éste. Asimismo, en el caso de las empresas con una única embarcación, el aviso solía empezar con mencionar el nombre del vapor. La impresión parece además reforzarse por la insólita medida de fijar el 1 de octubre como fecha máxima de suscripción de los pasajeros, es decir, un mes antes de la salida. Esta última ocurrencia induce a pensar que los promotores no disponían libremente del medio de transporte. De hecho, las navieras o los armadores solían apurar lógicamente hasta los últimos días, antes de dar por cerrada una gestión. Y finalmente, hay que precisar que ninguna de las denominaciones de los diez puntos de suscripción se correspondía con el de una compañía naviera. Se trataba en su mayoría del domicilio de consignatarios que solían desempeñar su labor de representación en sus respectivas ciudades para una o más compañías, y combinaban a menudo esta actividad con otros negocios propios de un pequeño comercio. En otros casos, como el de D. Ripol y Compañía de Barcelona o la alicantina Valle y Compañía, eran conocidas agencias de transportes, cuyos anuncios aparecían a diario en la sección comercial de la prensa local.

Suposiciones aparte, lo cierto es que finalmente ningún vapor mercante zarpó desde Valencia rumbo a Egipto en los primeros días de noviembre. La información diaria sobre el tráfico marítimo del puerto de Valencia, que solía publicarse en la prensa local, no indica ninguna operación de salida de un barco de las características citadas. Al mismo tiempo, no hay rastro de su presencia por el Canal en los varios testimonios y memorias de viajes a Suez. Por lo tanto, ni la posibilidad de asistir a un histórico e inolvidable acontecimiento, ni la labor promocional, fueron factores suficientes para que esta primera propuesta diera sus frutos. En cualquier caso, cabe señalar que a los anónimos organizadores tampoco les acompañó la suerte, si tenemos en cuenta la sobrevenida de un grave suceso político que estorbó, verosímilmente, la puesta en marcha de la iniciativa. El 25 de septiembre de 1869 hubo un levantamiento republicano federalista en Barcelona, que seguidamente se propagó en otras localidades de la península. En Valencia, los disturbios en contra del gobierno del General Prim alcanzaron su máxima intensidad.

38 La estimación procede del análisis de los «anuncios oficiales» de las convocatorias de las plazas públicas vacantes relativas al año 1869, que publicaba el Boletín Oficial del Estado, por aquel entonces Gaceta de Madrid.

39 Valdaliso (1992). 
Es bien sabido que España vivía una época muy agitada, culminada un año antes con el destronamiento de Isabel II. La legalidad y el orden público se veían constantemente amenazados por sublevaciones y motines. Por más que limitados geográficamente, estos sucesos eran el reflejo de un país inmerso de pleno en una situación de inestabilidad. Según un testimonio contemporáneo, ésta era la idea que se percibía también fuera de España. El escritor Eusebio Blasco, otro de los convidados españoles a la apertura del canal, lo resume perfectamente durante su breve estancia en Marsella, antes de embarcarse hacia Egipto en un vapor de la Messageries Impériales:

¿Cuándo podremos los españoles viajar por el extranjero sin que las gentes nos miren como a una cosa rara? Así nos miran. Cuando oyen nuestro acento y se convencen de que no somos ni americanos ni italianos, entonces [...] nos mide[n] de arriba abajo y exclaman: ¡Ah! ¡Un español! ¿Y diga Ud., hay ya paz en España? Este $y a$ vale un mundo ${ }^{40}$.

Resulta difícil saber hasta qué punto pudieron incidir negativamente estos últimos desordenes, y el alcance del efecto disuasorio sobre los potenciales clientes del viaje Istmo de Suez. Por un lado, sólo afectaron algunas regiones de la península. Por ejemplo, no hubo «resonancia alguna» en Madrid. Por el otro, los periódicos se hicieron eco de los incidentes, si bien con diferentes matices, pero todos coincidieron en recalcar el clima de tensión existente ${ }^{41}$. En resumen, se hacía evidente una vez más la notable dificultad en llenar un barco de touristas españoles, en especial cuando se trataba de un viaje tan largo y costoso. Al fin y al cabo, tal como ironizaba el escritor aragonés, para permitirse el lujo de presenciar el «suceso magno» no era imprescindible amar «la civilización y el progreso», sino ser más bien uno de los pocos afortunados en disponer «veinte o treinta mil reales», o en alternativa, haber recibido la invitación oficial del gobierno egipcio y viajar así gratuitamente ${ }^{42}$.

\section{EL CRUCERO DEL MERCANTE PELAYO}

A mediados de octubre, los primeros invitados españoles disfrutaban de sus primeros días de estancia en Egipto. Entre ellos estaba el entonces director del Museo del Prado, Antonio Gisbert, a quien el «temor de marearse» le había obligado a pasarse «sobre cubierta» toda la travesía de Marsella a Alejandría ${ }^{43}$. Mientras todo esto ocurría, el Diario de Barcelona divulgaba un escueto aviso promocional (figura 2).

40 Gil Blas, 21 de octubre de 1869, p. 3. Sobre el desplazamiento de la primera expedición de los invitados españoles, que tuvo lugar a primeros de octubre de 1869, véase Sacristán (1999).

41 Pérez Roldán (1998) pp. 296-301. Además de Cataluña, Valencia y Aragón, hubo desordenes menores también en Andalucía, Castilla la Vieja, Asturias y Galicia. Sólo a partir del 18 de octubre, con la rendición de los insurrectos de Valencia, la situación empezó a normalizarse.

42 Gil Blas, 14 de octubre de 1869, p. 2. El escritor hace referencia a los reales de vellón, siendo 4 reales equivalentes a 1 peseta.

43 El Imparcial, 23 de octubre de 1869, p. 1. 


\author{
Figura 2 \\ ANUNCIO DEL VIAJE DE RECREO \\ DESDE BARCELONA DEL BUQUE PELAYO (1869)
}

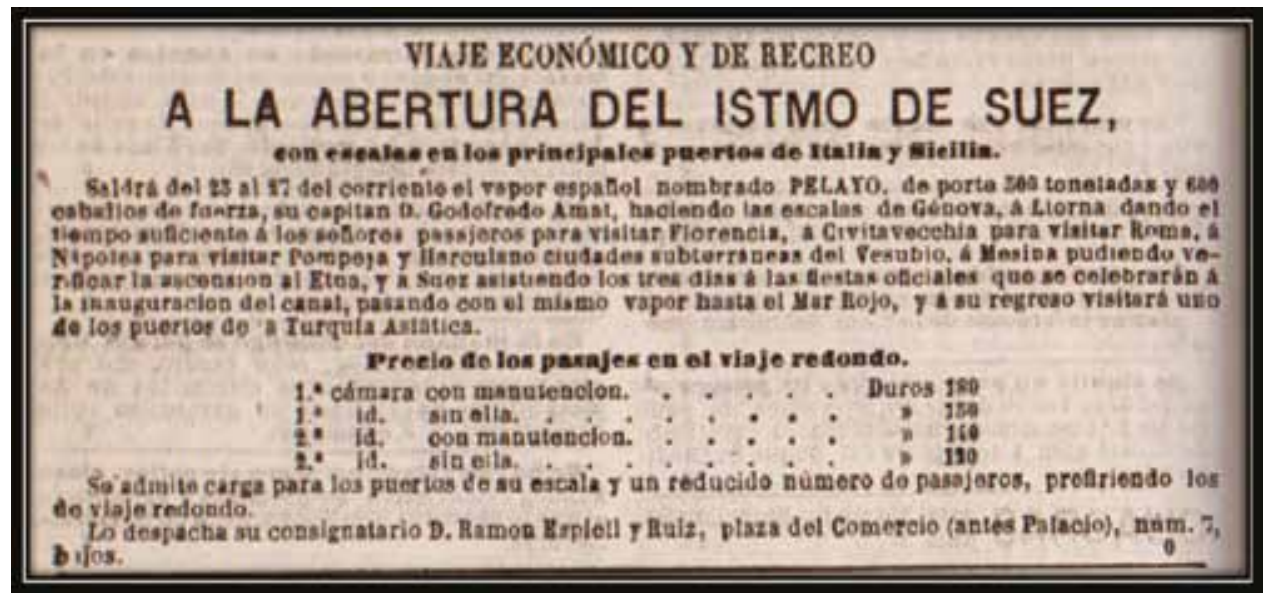

Fuente: Diario de Barcelona, 19 de octubre de 1869, p. 10490.

Publicado en la sección marítima, en la que se promocionaban algunas de las operaciones de transporte desde el puerto de la ciudad condal, el breve texto hacía referencia a la inminente salida de un buque vapor hacia Egipto, con el fin de asistir a las «fiestas oficiales» del Canal. El itinerario que se ofrecía a lo largo de la travesía por el Mediterráneo no se diferenciaba mucho del de un típico crucero de hoy en día, por lo menos en el trayecto de ida. Con salida de Barcelona, se incluía el tránsito por los puertos italianos de Génova, Livorno, Civitavecchia, Nápoles y Messina. De este modo, sugería el aviso, los pasajeros tendrían el tiempo «suficiente» para visitar Florencia, Roma, las ciudades de Pompeya y Herculano a los pies del Vesubio, e incluso «verificar la ascensión al Etna» durante la escala en Sicilia. Menos claro y detallado el trayecto de vuelta, teniendo en cuenta que después de participar en la inauguración del canal, sólo se concretaba el paso por un puerto de la Turquía asiática. Más allá de la programación, si nos fijamos en otros aspectos de la nueva propuesta de viaje, podemos apreciar algunas significativas diferencias de concepto y método con la expedición de Valencia. En primer lugar, se daba la oportunidad de poder elegir la acomodación entre dos distintas clases, y a un precio muy inferior: 900 pesetas en primera y 700 en segunda. Incluso se ofrecía para ambas clases otro nivel tarifario sin incluir el servicio de comida, obteniendo en tal caso una reducción respectivamente de 200 y 150 pesetas. Pero sobre todo, y con el claro objetivo de hacer frente a la habitual escasez de touristas, y asimismo rentabilizar la operación, se admitía el transporte de carga y un «reducido» número de pasajeros para los puertos de escala. Todas las pertinentes reservas se llevarían a cabo únicamente en el domicilio de la agencia consignataria Espiell y Ruiz, un pequeño comercio ubicado en plena Ciutat Vella de Barcelona. En definitiva, teniendo en cuenta el tipo de recurso publicitario utilizado, su ámbito de difusión y el breve tiempo de antelación respecto al 
día de salida, es evidente que se trataba de un proyecto de carácter local, dirigido a un público mucho más reducido, y por lo tanto más acorde con las primeras experiencias de crucero en España ${ }^{44}$.

De acuerdo con el anuncio, la expedición se efectuaría a bordo del Pelayo, un vapor de hélice con un «porte de 500 toneladas y 600 caballos». Como solía ocurrir a menudo en aquella época, los datos de la prensa sobre tonelaje y fuerza de los motores eran incorrectos, siendo en línea general este tipo de información de escasa fiabilidad. En realidad, como indica la documentación notarial, el buque de vapor con casco de hierro Pelayo, perteneciente a la matrícula de Barcelona, disponía de una máquina de $140 \mathrm{CV}$ y medía 350 toneladas de arqueo total, repartidas en 189 para la carga, 120 para maquinaria y carboneras, y 41 toneladas para las cámaras de popa y proa ${ }^{45}$. Al igual que la inmensa mayoría de los vapores españoles de la época, se trataba de un barco procedente de astilleros extranjeros, siendo éste fabricado en La Seyne-sur-Mer (Tolón). En su primera etapa (1853-1867), el buque de 54,9 m. de eslora, 7,5 m. de manga y 3,5 m. de calado, perteneció a la sociedad en comandita Bofill y Martorell, una de las primeras compañías marítimas de vapor catalanas nacidas a mediados de siglo, que lo había adquirido a una sociedad «en liquidación» de Marsella por el precio de 325.000 francos $^{46}$. A lo largo de esos años, el vapor mercante había recorrido inicialmente la ruta Cádiz-Marsella (y escalas intermedias), donde la naviera se había posicionado al principio de su actividad, efectuando su primera operación entre Barcelona y Marsella en abril de $1853^{47}$. Sucesivamente, había prestado servicio en la línea regular entre la península y el archipiélago canario en calidad de correo marítimo, por haber sido adjudicado a la Bofill y Martorell y Cía. el contrato del transporte de la correspondencia oficial entre 1860 y $1866^{48}$. A finales de esa década, dicha empresa se vio afectada por una grave crisis, al igual que otras navieras catalanas, lo que supuso el cierre de su actividad y la consecuente venta de sus activos. En la subasta pública celebrada el 2 de enero de 1868, una vez «comparadas las diversas proposiciones», los liquidadores de la sociedad procedieron a la venta del barco, por una cantidad de poco más de 45.000 pesetas, a favor de Juan García Solá, «rentista» de la ciudad de Barcelona, quien a partir de ese momento se convertía en propietario y armador del vapor ${ }^{49}$. Después de formalizar la escritura de compra en la Escribanía de Marina el 21 de enero de 1868, el buque no tardó en reanudar su actividad, efectuando su primera salida dos días después

44 Cerchiello (2013). Aunque la prensa madrileña se hizo eco de la noticia sobre el «viaje de placer», se trataba de una breve información procedente del Diario de Barcelona sobre la inminente salida del barco; véase por ejemplo La Discusión, 26 de octubre de 1869, p. 3; La Iberia, 27 de octubre de 1869, p. 3.

45 Archivo Histórico de Protocolos de Barcelona (en adelante AHPB), Escribanía de Marina, 10 de octubre de 1854, ff.os 201-203. Cabe recordar que hasta diciembre de 1874, el tonelaje de los barcos españoles hacía referencia a las toneladas Ciscar. Sólo a partir de esa fecha se introdujo el sistema internacional de medición (método Moorsom), siendo 1 tonelada igual a 2,832 $\mathrm{m}^{3}$.

46 Museo Marítimo de Barcelona (en adelante MMB), Registro de Marina, Fichero Vapores Españoles.

47 El Áncora, 16 de abril de 1853, p. 279. El Pelayo había llegado por primera vez a Barcelona procedente de Marsella el 27 de marzo de 1853, para ser «consignado a los Sres. Martorell y Bofill» y luego salió para Cartagena donde se formó su asiento, «con carácter provisional», el 7 de abril de 1853, antes de ser inscripto definitivamente en la lista de Barcelona el 27 de julio de 1853. Véase también MMB, Registro de Marina, Fichero Vapores Españoles; AHPB, Escribanía de Marina, 10 de octubre de 1854, ff. os 201-203.

48 Rodrigo (2007), pp. 69-71.

49 AHPB, Josep Falp, 2 de enero de 1868, ff. ${ }^{\text {s }}$ 3-4 y AHPB, Josep Falp, 7 de enero de 1868, ff. ${ }^{\circ}$. 27-29. 
con destino Marsella ${ }^{50}$. Con el traspaso de propiedad, el Pelayo fue empleado principalmente en la navegación de gran cabotaje entre Barcelona y Marsella, con escalas en los puertos de San Felíu de Guixols y Pálamos. No obstante, según la información de la prensa sobre el tráfico portuario de Barcelona, también se observan con cierta frecuencia operaciones por Valencia y sobre todo Tarragona. Se trataba en todo caso de salidas hacia transporte de carga, siendo muy esporádica la presencia de pasajeros.

Diferente de la habitual tuvo que ser, por tanto, la atmósfera que reinó a bordo del barco el 29 de octubre de 1869. Aunque el mal tiempo produjo un retraso de aproximadamente 48 horas en la programación, lo cierto es que el vapor Pelayo zarpó ese día del puerto de la ciudad condal. Bajo el mando del capitán Godofredo Amat, el buque emprendió «el viaje de recreo que tenía anunciado» ${ }^{51}$. Ninguna fuente consultada, por el contrario, facilita la exacta cuantía de los viajeros que finalmente embarcaron. El Diario de Barcelona informó únicamente que «entre otros» pasajeros figuraban unos «jóvenes muy conocidos en los principales círculos» de la ciudad, deseosos de aprovechar «esta circunstancia» para visitar las obras del Canal $^{52}$. Además, señaló que «a bordo de dicho buque» debía estar el arzobispo de Tarragona, Francisco Fleix y Solans, quien por el contrario se dirigía a Roma para asistir al Concilio Vaticano $\mathrm{I}^{53}$. Por otra parte, la falta de datos tampoco nos aporta información sobre la travesía, excepto una noticia, según la cual, el barco llegó a Génova tras 44 horas de navegación, «a pesar de los fuertes temporales» que arreciaban en el homónimo golfo ${ }^{54}$.

Mientras el Pelayo se dirigía a Egipto, otros vapores extranjeros seguían el mismo rumbo. Entre éstos estaba el Guienne, que había zarpado de Marsella «materialmente» lleno de viajeros de «todas las naciones». Al igual que el Pelayo, el buque francés tuvo que enfrentarse a unas condiciones meteorológicas muy adversas, en su caso, después de cruzar el estrecho de Messina. Entre los 150 pasajeros que transportaba el Guienne, se encontraban el citado catedrático de griego, Lázaro Bardón, y el escritor y periodista francés, Émile De La Bédollière. Ambos pasajeros han dejado un interesante relato sobre sus experiencias a bordo. Se describen por ejemplo los efectos de la borrasca y el «terrible balancear» del vapor de palas, que «a pesar de su gran mole» (1.600 toneladas) y joven edad (botado en 1860), se parecía a una «devanadera» llena de «enfermos inertes». El profesor español aporta una visión muy detallada y llena de humor sobre la incomodidad de los diminutos camarotes de la época:

Supóngase un espacio cerrado, capaz de dos metros de largo, dos de ancho y otros dos de alto, con una puertecita de persiana fija del medio arriba [...], cuatro camas

50 AHPB, Escribanía de Marina, 21 de enero de 1868, ff. ${ }^{\text {s }}$ 85-89. Diario de Barcelona, 24 de enero de 1868 , p. 795.

51 Diario de Barcelona, 30 de octubre de 1869, pp. 10872 y 10797. Entre las embarcaciones «despachadas» del día 29, figuraba el vapor Pelayo, con destino final Esmirna.

52 Diario de Barcelona, 29 de octubre de 1869, p. 10831.

53 Diario de Barcelona, 30 de octubre de 1869, p. 10782. El Concilio Ecuménico empezó oficialmente el 8 de diciembre y la participación del prelado de Tarragona, ya arzobispo de La Habana entre 1846-1864, se vio gravemente afectada por su precario estado de salud. Murió el verano siguiente antes de poder volver a su residencia en Tarragona.

54 La Discusión, 6 de noviembre de 1869, p. 3. 
inmóviles, una sobre otra, a guisa de nichos de cementerio [...], una cómoda clavada al suelo, con tres cajones y lavabos fijos encima [...]. Y todos los camarotes de proa eran lo mismo. Así que, a la hora de acostarse y levantarse, abundaba en escenas grotescas, por coincidir a menudo los cuartos posteriores de los unos con los órganos olfatorios de los otros ${ }^{55}$.

Muy parecido, a este propósito, el alegato del escritor francés:

Dans la cabine que je vais occuper, il n'y a pas moins de six lits superposés, et quels lits! Un homme obèse les écraserait tous successivement. Fasse le ciel que je n'occupe pas le rez-de-chaussée! Mais en fin, à la guerre comme à la guerre! Je ne me préoccupe pas des inévitables embarras du voyage, je ne vois que le but! ${ }^{56}$

Los testimonios de los dos viajeros no parecen una exageración. En línea general, el espacio del alojamiento en los medios de transporte marítimo siguió siendo muy reducido hasta finales del siglo XIX, incluso en primera clase. Un ejemplo de ello lo encontramos incluso veinte años después, en 1889, con el Reina María Cristina. Perteneciente a una nueva clase de vapores con máquina de triple expansión, el buque de la Compañía Trasatlántica, que fue destinado a operar entre España y las Antillas, disponía acomodación para 176 pasajeros de primera clase, repartidos en 59 camarotes. Según consta del acta oficial de reconocimiento y prueba del barco, ninguna cabina de dos literas en primera clase alcanzaba los $5 \mathrm{~m}^{2}$. Además, el promedio de los camarotes de triple ocupación en primera clase (3 literas inmóviles) era inferior a los $7 \mathrm{~m}^{257}$.

Volviendo a las travesías del Guienne y el Pelayo, ambos vapores consiguieron llegar a Puerto Said a pesar del mal tiempo. Más precisamente, el buque español lo hizo el 16 de noviembre en torno a las cuatro de la tarde ${ }^{58}$. Ese día, en la rada del puerto se encontraban «cargados» de pasajeros un total de aproximadamente 120 buques mercantes procedentes de «medio mundo». Muchos de éstos, según la costumbre de la época, estaban «elegantemente» empavesados por banderas y gallardetes en señal de fiesta. Junto a los buques mercantes, había unos 35 vapores de guerra. Uno de los primeros en llegar había sido la fragata española Berenguela, que representó al gobierno de España en la ceremonia de apertura del canal. Los escritos redactados por dos miembros de su tripulación, el segundo comandante Joaquín Navarro y el «joven» guardia marina Manuel Saralegui, así como las memorias de viaje de Arturo Baldasano, un integrante de la comisión oficial del Ministerio de Fomento que viajó a bordo del buque de guerra, ayudan a esclarecer algunos detalles sobre la actividad del «vapor de recreo» Pelayo en los días de la inauguración ${ }^{59}$. Ante todo, se tiene constancia de que éste participó efectivamente en el desfile oficial de las embarcaciones que recorrieron «lentamente» el canal. Debido al «sorteo de turnos» efectuado por las autoridades del puerto, al vapor Pelayo le tocó uno de los últimos pues-

55 Bardón (1870), pp. 8-10.

56 De La Bédollière (1870), pp. 4-14.

57 MMB, Fondo Compañía Trasatlántica, legajo 38

58 Véase el parte telegráfico en Diario de Barcelona, 17 de noviembre de 1869, p. 11493.

59 Respectivamente, Navarro (1870), pp. 101-103; Saralegui (1907), pp. 293-297; Baldasano (1870), p. 34. 
tos de la «comitiva naval». Por este motivo, su salida se efectuó solamente a las 10 de mañana del 18 de noviembre, es decir, aproximadamente 24 horas después de que zarpara, «en medio de salvas y de músicas», el primer barco con a bordo Ferdinand de Lesseps, Francisco José I de Austria, y Eugenia de Montijo, consorte de Napoleón III y madrina de la inauguración. Las crónicas sobre la estancia de la Emperadora de Francia en Port Said aportan los últimos pormenores sobre el Pelayo. Varios testimonios aseguran que una vez terminada la ceremonia religiosa de bendición del canal, que había abierto oficialmente los actos de inauguración, un reducido grupo de españoles dedicó una «extraña» serenata a Eugenia de Montijo. Entre ellos, además de varios tripulantes de la fragata de guerra Berenguela, estaba el corresponsal del diario madrileño La Época, José Castro, quien fue el primero en publicar con detalles el episodio. En su larga crónica, el reportero escribió que una de las coplas fue cantada por «uno de los pasajeros del vapor mercante Pelayo», pero añadiendo erróneamente que éste pertenecía a la «matrícula de Cádiz» ${ }^{60}$. Pues cuatro días después, el Diario de Barcelona hacía constar que «se decía equivocadamente que el vapor Pelayo que asistía a las fiestas del Istmo era de la matrícula de Cádiz, siendo así que lo es de la de Barcelona» ${ }^{61}$. Y finalmente, a causa del «excesivo» calado de la Berenguela, los organizadores de la ceremonia decidieron que el buque de guerra no podía unirse al desfile de los barcos hasta Suez. A razón de ello, una comisión de oficiales y marinos de la fragata efectuó el trayecto a bordo del Pelayo, siendo así el pequeño vapor de la matrícula de Barcelona el primer barco español en cruzar el célebre canal «bajo la bandera de la patria» ${ }^{62}$.

\section{CONCLUSIONES}

Con la llegada a Barcelona de los expedicionarios del Pelayo el 8 de diciembre, quienes se mostraron «muy satisfechos» de la experiencia vivida, el viaje marítimo de recreo había llegado a su fin ${ }^{63}$. En cuanto al pequeño buque mercante, el principal protagonista del suceso, volvió a las operaciones de cabotaje por la costa de Cataluña sin realizar ningún otro viaje de placer. En febrero de 1871, el vapor fue vendido por 30.000 pts. a dos «vecinos de la Barceloneta», y posteriormente convertido en un bergantín-goleta de tres palos ${ }^{64}$.

La clave del éxito del largo viaje a Egipto - el primero y único de estas características que se efectuó en España en el siglo XIX - fue la extraordinaria repercusión que tuvo en su momento la inauguración del Canal de Suez, un evento que por sí solo fue capaz de activar la participación de la reducida clientela de la época. Por el contrario, otros factores que hoy en día inciden en la decisión de realizar un crucero, como el itinerario, las localidades a visitar, y más aún las características del barco, no desempeñaban en esa época

60 La Época, 30 de noviembre de 1869, p. 2. También Baldasano (1870), pp. 43-44; Saralegui (1907), pp. 293-297.

61 Diario de Barcelona 4 de diciembre de 1869, p. 12121.

62 Navarro, 1870, pp. 36-41; Baldasano, 1870, pp. 45-52; La Época, 08 de diciembre de 1869, p. 2.

63 Diario de Barcelona, 9 de diciembre de 1869, p. 12333.

64 MMB, Registro de Marina, Fichero Vapores Españoles; AHPB, Pablo Cardellach, 11 de marzo de 1872, ffos. 217-219. 
un papel decisivo. Igualmente, tampoco se considera que ejercieron un peso determinante la duración y el precio del viaje, y aún más el hecho de que éste último estuviera por debajo de la cuantía exigida por los organizadores del primer crucero Istmo de Suez. Al fin y al cabo, los únicos que podían acceder a un producto tan exclusivo, como un viaje de placer a Egipto, eran los miembros de una élite libres de obligaciones personales, y con una muy elevada, sino ilimitada, capacidad de compra. Por este motivo, sí que resultó muy acertada la decisión del armador del Pelayo de rentabilizar la operación, mediante la combinación del viaje de recreo con el transporte de mercancías y demás pasajeros entre los diferentes puertos de escala, a diferencia de lo que se había establecido para la expedición de Valencia. Dicho de otra manera, quienes se embarcaron aquel 29 de octubre de 1869 a bordo del buque Pelayo, lo hicieron con el propósito de formar parte de un evento histórico, aprovechando la circunstancia del viaje organizado, y no viceversa. De hecho, no fue una casualidad que hasta los años veinte del siglo pasado, ningún otro crucero de larga duración llegó a materializarse en España. Por ejemplo, tampoco el viaje a Italia en verano de 1882 para «rendir un tributo de admiración» al recién fallecido Giuseppe Garibaldi, consiguió llevarse a cabo. La falta de pasajeros obligó a la compañía organizadora a abandonar el proyecto, y cancelar la salida desde el puerto de Barcelona ${ }^{65}$.

Este escenario contrasta claramente con lo sucedía fuera de España. En un contexto de expansión del negocio marítimo, simbolizado por la construcción de una nueva generación de buques especialmente diseñados para el transporte de pasajeros (los transatlánticos), varias compañías de línea empezaron a fomentar largas expediciones de placer entre las clases acomodadas extranjeras, ya sin la necesidad de emprender los viajes en coincidencia con algún acontecimiento de gran resonancia. En el último cuarto del siglo XIX, y de forma más clara en los primeros años de 1900, se fueron generalizando los largos cruceros elitistas desde Nueva York, Hamburgo, Southampton o Marsella, entre otros puertos de embarque. En línea general, se trató en ese transcurso de un fenómeno estacional, efectuándose las travesías en las temporadas de menor actividad del tráfico de línea. Esto respondía esencialmente a la exigencia de las compañías de buscar un mercado de sustitución, y compensar así su exceso de tonelaje. Especialmente activas se mostraron las navieras británicas ${ }^{66}$. Una de éstas fue la Orient Steam Navigation Company, la empresa creada en 1878 para operar en el servicio regular entre el Reino Unido y Australia. Entre 1889 y 1900, esta entidad puso en marcha un total de 95 cruceros desde distintos puertos británicos, incluyendo una expedición trasatlántica de 65 días a las islas del Caribe a finales de $1893{ }^{67}$. Pero al margen del considerable número de viajes efectuados, el verdadero rasgo diferencial de la Orient Line fue su firme apuesta por la novedosa modalidad recreativa. Muy pronto, de hecho, se convirtió en la primera compañía en organizar cruceros turísticos a lo largo de todo el año, incluso durante la temporada alta del servicio de línea ${ }^{68}$. A dar un impulso al desarrollo de esta modalidad, contribuyó la labor organizativa de algunas

65 El anuncio del viaje en La Vanguardia, 4 de julio de 1882, p. 4246. El itinerario propuesto por la compañía francesa, Valéry Frères et Fils, incluía las escalas en Marsella, Génova, Livorno, Nápoles, Civitavecchia y la pequeña isla de Caprera, con el propósito principal de visitar la casa y el sepulcro del «héroe de los dos mundos».

66 Cartwright y Harvey, (2004), pp. 11-14.

67 Williams (2000), pp. 3-6.

68 Id. 
grandes agencias de viajes, que emprendieron sus proyectos mediante el chárter del buque transatlántico. A la ya célebre Thomas Cook \& Son, fueron sumándose a principios del siglo XX otras empresas organizadoras, especialmente en el mercado norteamericano. La agencia Frank C. Clark, por ejemplo, efectuó en febrero de 1906 un crucero de 70 días hacia el Mediterráneo y Oriente Medio, a raíz del flete del Arabic de la naviera White Star Line ${ }^{69}$. El principal mérito de estas empresas fue favorecer el acceso al crucero de otros miembros de las capas altas de la sociedad, o mejor dicho de quienes estaban un peldaño por debajo de la tradicional clientela ultraelitista ${ }^{70}$. De hecho, sus iniciativas solían caracterizarse por ofrecer un amplio nivel tarifario, con una considerable diferencia entre los precios de venta en función de la ubicación, dimensiones y capacidad de ocupación de cada cabina. Otra de las aportaciones de estas empresas, fue la de mejorar la comercialización del producto, en virtud de la amplia red de oficinas, delegaciones y representantes que disponían. No en vano, cuando en 1903 la agencia Cook puso en marcha un crucero de Nueva York a Europa a bordo del buque Moltke, ya contaba con alrededor de 30 delegaciones repartidas en todo el mundo. Sin embargo, ninguna de éstas estaba en España ${ }^{71}$.

En definitiva, mientras el crucerismo asumía un protagonismo creciente en el extranjero, las élites españolas se mantuvieron alejadas de este fenómeno. Hasta bien entrada la década de 1920, el viaje marítimo de recreo en España mantuvo un carácter excursionista y de ámbito local.

\section{FUENTES Y BIBLIOGRAFÍA}

\section{Recursos archivísticos}

Archivo Histórico de Protocolos de Barcelona (AHPB), Escribanía de Marina (1854, 1868) y Notarios: Josep Falp (1868), Pablo Cardellach (1872)

Museo Marítimo de Barcelona (MMB), Registro de Marina, Fichero Vapores Españoles, y Fondo Trasatlántica, legajo 38.

\section{Diarios de viajes y otras fuentes primarias}

BALDASANO, A. (1870): De la Puerta del Sol a las Pirámides. Viaje al Istmo con escala en Jerusalem, Madrid.

BARDÓN, L. (1870): Viaje a Egipto con motivo de la apertura del canal de Suez y excursión al mediodía de Italia, Madrid.

BREITTMAYER, A. (1870): Inauguration du Canal Maritime de l'Isthme de Suez. Note de voyage, Lyon.

Cook's Cruise to the Mediterranean, the Orient and Bible Lands, Thomas Cook Ltd., Nueva York, 1902.

Constitution de la Compagnie universelle du canal maritime de Suez: pièces et documents officiels, Chaix, París, 1873.

69 New York Daily Tribune, 5 de enero 1906, p. 13

70 Williams (2000), p. 3.

71 Cook's Cruise to the Mediterranean, the Orient and Bible Lands (1902). 
DE LA BÉDOLLIÈRE, É. (1870): De Paris a Suez. Souvenirs d'un Voyage en Égypte, París.

DE SANTOS, E. (1851): Diario del viaje desde Madrid a Manila, Madrid.

Diario de Sesiones de las Cortes Constituyentes, Tomo VII, Madrid, 1870.

GARCÍA DEL CANTO, A. (1862): Guía del viajero desde Madrid o Cádiz a Manila por el Istmo de Suez y por el Cabo de Buena Esperanza, Madrid.

Legislación Ultramarina, Tomo I, Ministerio de Ultramar, Madrid, 1865.

MINISTERIO DE MARINA (1871): Lista oficial de los buques de guerra y mercantes de la marina española de 1871, Madrid, Depósito Hidrográfico.

MONTESINO, C. S. (1857): Rompimiento del Istmo de Suez, Madrid, Imprenta Nacional. NAVARRO, J. (1870): Canal de Suez. Paso de la Berenguela por el mismo, Madrid, Imprenta Nacional.

ORTIZ DE ZARATE, D. (1848): Viaje por el Istmo de Suez, desde China a Europa, y de Europa a China, Manila.

\section{Recursos periodísticos}

Diario de Barcelona $(1868,1869)$

Eco de Alicante (1869)

El Áncora (1853)

El Clamor Público (1856)

El Imparcial (1869)

El Museo Universal (1869)

Fraser's Magazine (1856)

Gaceta de los Caminos de Hierro (1856)

Gaceta de Madrid (1845)

Gil Blas (1869)

La Correspondencia de España (1869)

La Discusión (1869)

La Época $(1856,1869)$

La Iberia (1869)

La Ilustración (1856)

La Stampa (1869)

La Vanguardia (1882)

New York Daily Tribune (1906)

\section{BIBLIOGRAFÍA}

AZCÁRRAGA, J.L. (1956): «Régimen Jurídico del Canal de Suez», Revista de Política Internacional, $\mathrm{n}^{\circ} 27, \mathrm{pp} .49-60$.

BERNERON, M.F. (2007): Les Messageries Maritimes. L'essor d'une grande compagnie de navigation, París, Université Paris-Sorbonne.

BERTRAND, A. y FERRIER, E. (1887): Ferdinand de Lesseps. Sa Vie, Son Euvre, París, Charpentier. 
CARTWRIGHT, R. y HARVEY, C. (2004): Cruise Britannia. The story of the British cruise ship (Brimscombe: Tempus, 2004), pp. 22-33.

CERCHIELLO, G. (2011): «Los albores del crucerismo en la España del siglo XIX (18481865)», Transportes, Servicios y Telecomunicaciones, $\mathrm{n}^{\circ}$ 20, pp. 158-186.

CERCHIELLO, G. (2013): La evolución del crucerismo en España. Desde sus orígenes hasta la actualidad (1848-2013), Tesis Doctoral, Universidad de Alicante.

DI NOLFO, E. (1959): «Il problema delle comunicazioni tra India e Gran Bretagna prima dell'apertura del Canale di Suez: l'Overland Route», Economia e Storia, n 2, pp. 164-182.

HAZBUN, W. (2007): «The East as en Exhibit, Thomas Cook \& Son and the Origins of the International Tourism Industry in Egypt», en The Business of Tourism. Place, Faith and History, Philadelphia, University of Pennsylvania, pp. 3-33.

HINOJO ROJAS, M. (2008): «El régimen jurídico de la navegación por el Canal de Suez», Anuario de Derecho Marítimo, $\mathrm{n}^{\circ}$ 25, pp. 169-200.

HOWARTH, D. y HOWARTH, S. (1987): The Story of P\&O: Peninsular and Oriental Steam, Londres, Weidenfeld \& Nicolson.

JOUHAM, E. (1878): Les opérations maritimes commerciales et industrielles à Marseille: comparaisons statistiques, résultats économiques, París, Amyot.

KARABELL Z. (2003): Parting the Desert: The Creation of the Suez Canal, Nueva York, Knopf.

LAVAUR, L. (1977): «Albores del turismo moderno (1850-1870). 2ª parte», Estudios Turísticos, $\mathrm{n}^{\circ}$ 54, pp. 9-40.

Los males y los remedios para las naciones civilizadas, Tomo II, Madrid, Elizalde, 1869.

MANSO DE VELASCO, J.A. (1947): «La inauguración del Canal de Suez contada por un bilbaíno», Boletín de la Real Sociedad Vascongada de Amigos del País, $\mathrm{n}^{\circ} 3$ (1), pp. 29-44.

MONTERO, F. J. y BOCANEGRA, A.R. (1998): «El Canal de Suez y su impacto en la economía internacional», en Estudios de la Universidad de Cádiz ofrecidos a la memoria del profesor Braulio Justel Calabozo, Cádiz, Universidad de Cádiz, pp. 609-620.

PÉREZ, M ${ }^{\mathrm{a}}$.C. (1998): Bases sociales del republicanismo madrileño (1868-1874), tesis doctoral, Universidad Complutense de Madrid.

PIQUET, C. (2008): «La Compagnie du Canal de Suez. Una Concession Française en Égypte (1858-1956), Entreprises et Histoire, n 52, pp. 67-75.

POOLE, S. y Sassoli-Walker, A. (2013): $P \& O$ Cruises. Celebrating 175 years of Heritage Amberley, Gloucestershire.

RODRIGO, M. (2007): «Navieras y navieros catalanes en los primeros tiempos del vapor 1830-1870», TST, $\mathrm{n}^{\circ} 13$, pp. 63-92.

SACRISTÁN, F.J. (1999): «La gran expedición al alto Egipto enmarcada en los actos de inauguración del Canal de Suez», Boletín de la Asociación Española de Egiptología, $\mathrm{n}^{\mathrm{o}}$ 9, pp. 251-258.

SARALEGUI, M. (1907): Recuerdos y rectificaciones históricas, Madrid.

VALDALISO, J.M. (1992): «La transición de la vela al vapor en la flota mercante española: cambio técnico y estrategia empresarial», Revista de Historia Económica, $\mathrm{n}^{\circ} 1$, pp. 63-98. 
WILLIAMS, D. (2000): «Market Pressures and Innovation: The Orient Steam Navigation Co. and the Development of Pleasure Cruising, 1888-1900», The Northern Mariner/ Le Marin du nord, $\mathrm{n}^{\circ}$ 10, pp. 1-12.

WILLIAMS, D.M. y ARMSTRONG, J. (2005): «The steamboat and popular tourism», Journal of Transport History, ${ }^{\circ}$ 26, pp. 61-77.

WILLIAMS, D.M. y ARMSTRONG, J. (2006): «Steam shipping and the beginnings of overseas tourism: British travel to North-Western Europe, 1820-1850», Journal of European Economic History, $\mathrm{n}^{\circ}$ 35, pp. 125-148.

WITHEY, L. (1997): Grand Tours and Cook's Tours, Nueva York, William Morrow and Company. 
